\title{
BAUDELAIRE VENAL
}

\author{
Cristian Molina \\ Universidad Nacional de Rosario \\ Instituto de estudios críticos en Humanidades \\ Consejo Nacional de Investigaciones Científicas y Técnicas \\ molacris@yahoo.com
}

\begin{abstract}
Resumen: En el presente trabajo abordo las relaciones entre escritura y mercado que Baudelaire propicia en diferentes textualidades. Me interesa focalizar en la multiplicidad de sentidos que adquieren dichas relaciones en un régimen de venalidad.
\end{abstract}

Palabras clave: Venalidad, Poesía, Mercado, Moneda viviente.
Asbtract: In the present text I work the relationships between writing and market that Baudelaire promotes in different textualities. I am interested in focusing on the multiplicity of meanings that these relationships acquire in a regime of venality.

Keywords: Venality, Poetry, Market, Living coin. 
Comienzo con un poema de Les fleurs du mal, de Charles Baudelaire, que no dejó de intrigarme en su lectura cada vez que volvía a él. Incluso en las clases, ante los estudiantes, ese poema hacía enmudecer el sentido cuando les preguntaba qué podían leer allí. Entonces, el silencio era una especie de complicidad compartida y prolongada, no porque nos hubiéramos quedado sin palabras, sino porque el poema parecía convocarlas en torrentes, a veces caóticos y diferentes (otras, opuestos), que dificultaban asegurar algo sin tropezarnos con un resto inasible o, mejor dicho, con una incertidumbre mayor. Ahora que intento escribir sobre ese poema, sospecho que todo puede arruinarse -en tanto volverse una ruina indescifrable- en el tiempo que dure esta exposición, pero que, al menos, será una tentativa en la que no estaré solo porque ya forma parte de un viejo intento fallido colectivo.

Se trata de "La Muse Vénale", unos de los sonetos iniciales del libro, incluido en la sección primera "Spleen et ideal" y que aparece ya en la edición de 1857. Lo primero que intriga en el poema es el tono múltiple que uno advierte. Porque si bien abre con un vocativo, no se trata de una mera invocación a la musa para comenzar el canto o la escritura o el decir poético, casi en el inicio del libro, ya que la "musa enferma" acaba de ser exhortada apenas una página antes $y$, por ende, la invocación quedaría deflacionada por repetición. Sin embargo, ese tono parece estar más dirigido a interrumpirse con un lamento o una queja -no sabemos bien qué- en forma de preguntas en los cuartetos que terminan por coagularse como una necesidad a la que estaría sometida, casi una obligación ("Il te faut") en los tercetos.

$N^{\circ}$ 8. Primer Semestre de 2018 
Tanto si leemos la hipótesis de un paulatino pasaje del ideal a una caída en el spleen, como entiende Pichois esta parte del libro (OC., 1976) o si, como propone Américo Cristófalo, "Spleen e ideal nombran un rasgo decisivo de Les fleurs du mal: lo doble, dos fuerzas en tensión que dialogan de entrada" (2008, p. 18), lo cierto es que la musa, entre la invocación, la necesidad, la pregunta, la queja y el lamento coagula un conjunto múltiple de pathos y tonos. Y esa multiplicidad se da en torno de su adjetivación: "vénale". En la lengua francesa, la palabra vénale, que proviene del latín venalis, al igual que en el español, tiene el significado de "relativo a la venta". Pero hay un uso eufemístico que es exclusivo de la lengua francesa, "vénale" puede calificar a "femme" y remite a prostituta. Este uso es prácticamente inusual en español, salvo con connotaciones metafóricas. Pero lo cierto es que así, la musa divina, baja a tierra y se conecta con la ambigua heroicidad de las mujeres devenidas prostitutas, joyas, queridas, diferenciadas de las mujeres monstruosas en tanto esposas, pero todas insaciables y criaturas del deseo voluptuoso, que exigen riqueza y que ponen en vilo al poeta, en el límite de su desaparición como tal, encarnando una de las caras del mal en el imaginario baudelaireano.

La bifurcación en la calificación de la musa en venta / de la musa prostituta despliega toda la ambigüedad del poema en torno de la explicitación de la relación entre economía y poesía, que son dos caras, nuevamente, del spleen y el ideal. Porque, ¿cómo comprender las preguntas del poema? ¿Son una queja por el futuro en ayunas que le depara al poeta, debido la improductividad de la musa? ¿Son un lamento frente al 
presente en el que el poeta debe venderse como una prostituta para no tener el "palais" seco -anudamiento rímico entre dos palais que son en momentos diferentes palacio y paladar, como si la multiplicación afectase al sentido de una misma palabra en dos momentos diferentes del poema para enfatizar la ruina o casi el esplendor de la ruina entre un palacio y un paladar seco? ¿Son una arenga o invocación para que la musa actúe y produzca algo que pueda venderse en el mercado? ¿O todos ellos y más?

Esta "venalidad" de la musa no es exclusiva del poema de Les feurs $d u$ mal. Reaparece extendida, en la escritura baudelaireana, en sus corrrespondencias, críticas y pequeños poemas en prosa. En «Comment on paie ses dettes quand on a du Génie», Baudelaire relata en tono bastante irónico un contrato de Balzac para la gran prensa periódica, que es escrito por un ghost writer, pero firmada por él. El texto está recorrido por alusiones a la figura de Balzac como la cabeza más fuerte en lo comercial y literario del S XIX, o tapizada de cifras como el cabinet de un financista. Es decir, por una tensión entre lo económico y poético que parece, al menos, hasta el final, tener un tono bastante sarcástico - peyorativo- y casi chismoso respecto de la aventura balzaciana. Sin embargo, allí, nuevamente la venalidad baudelaireana genera una ambigüedad que pone en cuestión todo lo leído hasta el momento: "he querido mostrar que el gran poeta sabía deshacer un pagaré tan fácilmente como el novelista más misterioso e intrigante", asegura. La venalidad del poeta es análoga a la del novelista. El pago por un trabajo menor en la prensa se descubre como un cambio que une a novelista $y$ 
poeta, más que separarlos, y aquí, nuevamente, algo se anuda para desanudarse, como siempre, en la venalidad baudelaireana, porque, en efecto, la ironía se apaga en la homologación; el chisme se vuelve la revelación de una verdad que une a poeta y novelista en la subsistencia en ese mercado de la prensa periódica. ¿El genio paga sus deudas vendiendo su nombre como mercancía? ¿O en esa venta, finalmente, es la forma en la que el genio puede subsistir en ese mercado porque se lo permite el nombre, la función autor? La cuestión no parece ser lineal ni unívoca. Mucho menos si en estas venalidades que parecen regir las relaciones de Baudelaire con el mercado en el terreno de su escritura, hacemos intervenir sus cartas. En una a Poulet Malassis del 13 de diciembre de 1862, Baudelaire escribe:

En cuanto a Salammbö, un gran, gran éxito. Una edición de dos mil agotada en dos días. Positivo. Hermoso libro, lleno de defectos, enfurece a todos los revoltosos, particularmente a Babou. Hay quienes le reprochan a Falubert la imitación de los antiguos. Lo que hizo Flaubert, solo él pudo haberlo hecho (Baudelaire, 2005, p.159).

El yo que allí se escribe tira por la borda la regla de proporción inversa como criterio de valoración artística, que presupondría que a mayor éxito económico, menor poder simbólico y reconocimiento, según Pierre Bourdieu (2006). Puesto que, por el contrario, Baudelaire se encarga cuidadosamente de defender en esa carta, donde detalla la cifra millonaria ganada por Flaubert, el éxito económico tanto con 
la nueva novela, como con Madame Bovary, y en la cual rechaza cualquier argumento en contra de la calidad de la misma; a pesar del éxito y de los posibles defectos, no hay valoración negativa sobre ella. Un franco desafío a esa regla bourdiana, que, en otras ocasiones, como en la carta del señor de Saux del 30 de diciembre 1861, parece, no obstante, reponer:

Mil francos, por ejemplo. Para mí significaría una seguridad de tres meses. Hace más de tres años que duerme en mi habitación un drama destinado a un gran teatro de boulevard. (...) Es ciertamente una buena idea, y nosotros, poetas, estamos constreñidos a refugiarnos en un medio excéntrico, ya que los centros literarios (como la Comédie Française) no quieren representar más que grandes vaudevilles sin estrofas" (Baudelaire, 2005, p. 143).

En ambas cartas, se trata de afirmar no solo el deseo sino la aspiración al dinero por parte del artista, pero en esta segunda, la regla de proporción inversa, al tiempo que se afirma, porque marca la excentricidad de la práctica poética en el mercado y la hegemonía de ciertas piezas de teatro destinadas al público amplio, se pone en tela de juicio: porque se aspira a introducir en ese mercado, a venderse, incluso masivamente en el boulevard, una obra de arte con estrofas, diferente. Nuevamente, el arte (la poesía que dicta la musa) y el mercado se sostienen en un régimen de venalidad que difumina una posición única, prestablecida, de una vez y para siempre. Difumina cualquier regla. Entre los palais posibles, entre los cielos azules y el pan de cada día, entre el diácono y el saltimbanqui en ayunas, entre el éxito simbólico y económico, 
entre el fracaso simbólico por el éxito económico de las piezas de boulevard, las relaciones entre poesía y mercado se complejizan a un punto tal de que cualquier toma de partido ante ellas encuentra en la misma escritura de Baudelaire una difuminación.

$\mathrm{Y}$ ya que hablamos de saltimbanquis en ayunas como un rasgo posible -pero no unívoco- de esa venalidad de las relaciones, del régimen venal entre poesía y mercado en Baudelaire, es en "Le vieux saltimbanque" donde, entiendo, la escritura anuda un puntito de pensamiento que nos permite intentar, al menos, tocar un poco más lo que estos derroteros traen consigo. Ese puntito, entiendo, está dado por la equiparación del viejo saltimbanqui con el hombre de letras que aparece sobre el final. Luego de su alejamiento de la multitud festiva, que arrastra al poeta y le impide darle una limosna a esa ruina del hombre de letras, confiesa el douleur por la visión que acaba de tener ante la ingratitud pública, en la pobreza absoluta. El saltimbanqui en ayunas de "La Muse Vénale" deviene el hombre de letras empobrecido y excluido de la fiesta social en este poema en prosa. El palacio se convirtió en paladar seco. Uno podría observar aquí un viraje de la escritura tardía de Baudelaire. Sin embargo, el fantasma de la pobreza recorre su escritura como una ruina a la que arrastra el tiempo a la vida moderna, desde sus primeros poemas hasta en los ensayos críticos. Estaba en el dudoso paladar seco de la musa venal, aparece en "la moneda falsa", en los mendigos, en los ojos de los pobres, en los traperos que atraviesan la escritura de Baudelaire. 
Esta miseria absoluta como residuo del tiempo que "mange la vie" convierte en un fantasma al saltimbanqui y al hombre de letras en medio de la fiesta. Una fiesta de consumo que arrastra en el presente al que escribe, mirando su futuro fuera de la fiesta. Y es allí donde el poema pone en evidencia la tensión entre oikonomia y polis en tanto regímenes de la vida que tensan el tiempo que le toca al poeta. Emerge la vida del poeta en plena modernidad, en la ciudad de Paris, en el seno de una cultura capitalista que se tironea entre los asuntos domésticos de la economía para vivir y los asuntos éticos de la polis donde se vive, en cuanto toma de posición ante esa necesidad que no deja nunca de advertirse corporal y que remite a la posibilidad de subsistencia del cuerpo como la garantía de la vida. Ha sido Giorgio Agamben (2008) en El reino y la gloria, quien sostuvo que, desde la antigüedad, pero con un derrotero que se intensifica a partir de inflexiones en el medioevo, en el S XVIII y en el S XIX, los modos de regulación social se debatieron entre la oikonomia y la polis, la economía y la política. En Baudelaire, la tensión está dada por la oikonomia como fuerza del capitalismo que coloniza la vida del S XIX al punto de que en la literatura, como sostienen Regina Gagnier (2000) y también Franco Moretti (2014), generó una invasión de adjunciones como descripciones de artículos de lujo en el plano de la ficción realista, y al mismo tiempo una particular política que tiene que ver con una posición ética que se traslada en una oscilación incierta en la escritura, una apertura del sentido que también cuestiona esa oikonomia en la que sin embargo se es. Quiero decir, la venalidad en Baudelaire puede leerse también como respuesta a la vida en común, pero no 
común, de la necesidad económica como modo de subsistencia en el capitalismo avanzado y a la vida del hombre de letras que intenta proponer una ética y una política no común para sobrevivir. No se trata, desde ya, temporalmente estamos en otro mundo, de una supervivencia pasoliniana en el sentido de Didi-Huberman (2012), en un claro desde donde se ven las luces de las luciérnagas alejadas de las grandes luces del fascismo, si no de los trazos de una supervivencia que intenta encontrar un modo de hacer visible las luciérnagas en el medio de la gran luz del capitalismo del S XIX, aunque ello implique transformarse en una ruina, decadente, que esplende en sus fosforescencias oxidadas.

Y esto es consustancial con la práctica de Baudelaire en el mercado decimonónico. Tomemos como acercamiento las lecturas que Antoine Compagnon (2014) propone respecto de la publicación de los pequeños poemas en prosa en periódicos y revistas de gran y pequeña tirada en el S XIX, de los pagos y las tensiones entre Baudelaire y los editores de la prensa periódica. Sabemos que "Le vieux saltimbanque", por ejemplo, aparece publicado en la Revue fantaisiste, dirigida por Catule Méndes, en noviembre de 1861 y también en La Presse, en un sistema de cobro doble a partir de republicaciones, antes de su edición póstuma en libro. Generalmente, las publicaciones de los pequeños poemas en prosa en periódicos ocupaban el lugar del fouilleton tanto en los diarios de gran tirada como en los pequeños; es decir, el espacio de ese género redituable destinado a las masas. Ese gesto, no se trata meramente de un acercamiento concreto entre el poeta y el novelista, como proponía el final de «Comment on paie ses dettes quand on a 
du Génie », si no, además, como sostiene Compagnon, de un experimento fallido completamente diferente a su escritura anterior cuando se proponía convertir en un texto redituable como el fouilleton al pequeño poema en prosa, lo que implicó, desde ya, una articulación con la información y con la noticia como material poético. Baudelaire no solo recibía dinero a cambio de esas publicaciones, convirtiéndose en una especie de changarín o trapero, según Benjamin, sino que, además, intentaba, como declaraba en sus cartas, meter en el terreno del boulevard un poema (en este caso, en prosa). Y, al mismo tiempo, no dejaba de manifestar una posición hostil hacia la prensa y hacia las relaciones que implicaba ésta, al punto tal de que la cuarta tirada de los poemas en La Presse, fueron suspendidos en 1862 por Arsène Houssaye y, se sospecha, posiblemente fue por presión de los acreedores del periódico, disgustados, en parte, por esos venenitos contra la prensa y los lectores que Baudelaire introducía en el lugar del fouilletón. ¿O no es eso lo que arrastra el viejo saltimbanqui? ¿No son esas grandes masas de la feria, también los lectores del periódico? Tironeado, entonces, entre la prensa y la poesía, entre la oikonomia y la polis, Baudelaire devenía venal, como la musa, en su relación con el mercado. Y en esa venalidad lo vemos publicar y cobrar con gusto por ello, meter venenitos en los poemas contra la prensa y sus lectores, protestar con su madre porque no le publican sus poemas, dedicarle, sin embargo, a Houssaye el prólogo a Le Spleen de Paris.

Una venalidad que cuestiona las imágenes meramente heroicas de Baudelaire en la cultura capitalista, al tiempo que su lugar de nomoteta de la autonomía estética del siglo XIX. 
Como sostiene Marguerite S. Murphy (2012), se convirtió en un lugar común de la academia proponer la figura de Baudelaire ligada a la autonomía estética, sin reparar, por ejemplo, en las relaciones existentes entre los discursos económicos del siglo XIX con las propuestas estéticas, así como las reflexiones baudelaireanas distaban bastante de ser específicamente poéticas, literarias e incluso artísticas y estaban atravesadas por otras discursividades del siglo XIX (pintura, moda, economía, política, filosofía). La venalidad de las relaciones entre Baudelaire y el mercado, que dejan huellas en su escritura, en una verdadera tensión, se resuelve de manera múltiple en cada momento, empalmando tonos y registros que abren la lectura a interrogantes y sentidos siempre expansibles. Como sostuvo Derrida (1995) en Dar el Tiempo I. La moneda falsa, si se trata de una escritura del don que no puede identificarse como tal, eso se debería a que es una especie de máquina de producir acontecimientos; una escritura que no tiene un fin asignable, pero que sin embargo es siempre propicia a una escena de engaño: "únicamente una vida puede dar, pero una vida en la cual se presente y deje desbordar esta economía de muerte" (p. 65). Ese desborde de la vida, como lugar de la errancia en la tensión entre la oikonomia y la polis de la escritura, no hace sino multiplicarse, devenir, reincidir, proliferar en su venalidad.

Pero si lo hace es porque la palabra está próxima, lo que no quiere decir que es, a "una moneda viviente". Es Pierre Klosowski (2011) quien lee a partir de Sade la gran tentativa del capitalismo: una relación estrecha entre presencia corporal y dinero, que convierte al cuerpo en equivalente del dinero, 
aún a costa de desgastarlo. Es decir, una vuelta moneda del objeto viviente que, si bien puede suplantar al patrón productivista del oro e instituirse ella misma en valor, requiere un intercambio por objetos de sensación que también cuestan y que necesitan un equivalente cuantificable en trabajo. La venalidad de Baudelaire proviene de esa economía subyacente en el sadismo, donde el esclavo y el amo, si bien mantienen sus posiciones sociales y de poder, pueden, a través de objetos de sensación elaborados o conseguidos mediante sus cuerpos como monedas vivientes, invertir o acercar y a veces hasta destruir esas diferencias y distancias. Por eso, la venalidad remite a la vida y a la necesidad corporal, al tiempo que al orden del deseo, porque es palabra de una moneda viviente, de un cuerpo de poeta, que interviene en un mundo en donde tiene que ganarse su valor.

\section{Referencias Bibliográficas}

Baudelaire, C. (2008). Las Flores del Mal. Buenos Aires: Colihue. Introducción y traducción Américo Cristófalo.

---. (2005). Correspondencia general. Buenos Aires: Paradiso. Traducción de Américo Cristófalo.

---. (1976). Ouvres Complètes. Tomo I y II. Estudio y notas de C. Pichois. París: Gallimard, Bibliothèque de la Pléiade.

Agamben, G. (2008). El reino y la gloria. Buenos Aires: Adriana Hidalgo.

Bourdieu, P. (2006). Las reglas del arte. Barcelona: Anagrama. 
Compagnon, A. (2014). Baudelaire. L'Irréductible. París: Flammarion.

Derrida, J. (1995). Dar el Tiempo I. La moneda falsa. Buenos Aires: Paidos.

Didi-Huberman, G. (2012). La supervivencia de las luciérnagas. Madrid: Abada.

Moretti, F. (2014). El burgués. Entre la historia y la literatura. Buenos Aires: Fondo de Cultura Económico.

Klosowsky, P. (2011). La moneda viviente. Buenos Aires: Las cuarenta.

Murphy, M. S. (2012). Material Figures: Political Economy, Commercial Culture, and the Aesthetic Sensibility of Charles Baudelaire. Amsterdam: Rodopi.

Gagnier, R. (2000). The Insatiability of Human Wants: Economics and Aesthetics in Market Society. Chicago: University of Chicago Press. 